\title{
Optimal Support Solution for a Soft Rock Roadway Based on the Drucker-Prager Yield Criteria
}

\author{
Minghui Ma ${ }^{1,2}$, Qifeng Guo ${ }^{1, *}$, Jiliang Pan ${ }^{1, * \mathbb{C}}$, Chi Ma $^{1}$ and Meifeng Cai ${ }^{1}$ \\ 1 School of Civil and Resource Engineering, University of Science and Technology Beijing, Beijing 100083, China; \\ b20190007@xs.ustb.edu.cn (M.M.); d202110033@xs.ustb.edu.cn (C.M.); caimeifeng@ustb.edu.cn (M.C.) \\ 2 Shandong Gold Mining (Laizhou) Limited Company Jiaojia Gold Deposit, Laizhou 261400, China \\ * Correspondence: guoqifeng@ustb.edu.cn (Q.G.); b20170008@xs.ustb.edu.cn (J.P.)
}

check for updates

Citation: Ma, M.; Guo, Q.; Pan, J.; Ma, C.; Cai, M. Optimal Support

Solution for a Soft Rock Roadway Based on the Drucker-Prager Yield Criteria. Minerals 2022, 12,1. https:// doi.org/10.3390/min12010001

Academic Editors: Diyuan Li, Zhenyu Han, Xin Cai, Shijie Xie and Yosoon Choi

Received: 9 November 2021 Accepted: 13 December 2021 Published: 21 December 2021

Publisher's Note: MDPI stays neutral with regard to jurisdictional claims in published maps and institutional affiliations.

Copyright: (c) 2021 by the authors. Licensee MDPI, Basel, Switzerland. This article is an open access article distributed under the terms and conditions of the Creative Commons Attribution (CC BY) license (https:/ / creativecommons.org/licenses/by/ $4.0 /)$.
Abstract: Through theoretical calculation, the stress and deformation of surrounding rock can be analyzed, providing guidance for the support design and optimization of soft rock roadways. In this paper, theoretical solutions for both the optimal support pressure and the allowable maximum displacement of surrounding rock are derived from the Drucker-Prager (DP) yield criteria and the steady creep criterion expressed by the third invariant of deviator stress. The DP criterion with different parameters is compared and analyzed with an engineering example. Then, based on the calculation results the effects of long-term strength, cohesion, and internal friction angle of soft rock on the maximum plastic zone radius and allowable maximum displacement of roadway are discussed. The results show that the optimal support solution of soft rock roadways based on the DP criteria can not only reasonably reflect the intermediate principal stress but can also be used to compare and discuss the influence of different DP criteria on the calculation results. The higher the long-term strength of the rock surrounding a roadway is, the smaller the optimal support force is and the larger the allowable maximum displacement is. When the calculated long-term strength of soft rock can ensure that the deformation of the roadway does not exceed the allowable maximum displacement, the roadway can maintain long-term stability without support. With an increase in the cohesion or internal friction angle of soft rock, the radius of the plastic zone decreases gradually and the allowable maximum displacement is reduced by degrees. The use of grouting and other means to improve the strength of surrounding rock can effectively reduce the roadway deformation and save support costs. This new theoretical solution can consider different intermediate principal stress effects and different DP strength criteria, enabling the parameters to become easier to determine. It has a wider range of applications, and the calculation results better demonstrate the strength potential of the surrounding rock.

Keywords: roadway; soft rock; optimal support; Drucker-Prager yield criteria; elasto-plastic analysis

\section{Introduction}

Rock roadways exist widely in underground spaces, such as mining engineering, civil engineering, and tunnel engineering works. For deep geotechnical engineering works, some roadways will gradually transform from shallow hard rock roadways to deep soft rock roadways. Therefore, the problem of soft rock support has become a major safety issue that needs to be solved urgently [1-3]. Soft rock has obvious creep deformation characteristics. In engineering, serious extrusion deformation will occur in all directions of the roadway, which can lead to the instability and failure of the surrounding rock support structure [4-7]. In the process of the support design of soft rock roadways, it is generally necessary to optimize the support parameters reasonably by theoretical calculation, guide engineering design through theoretical calculation results, and reduce the uncertainty caused by the engineering analogy method used [8-10].

In the process of underground roadway excavation, the stress field will redistribute around the excavation area. The redistribution of the stress field leads to convergence 
deformation of cavities produced by excavation. The size of deformation is related to rock mass properties, in situ stress, and support conditions [11-14]. It is important to analyze the distribution of the stress field and the displacement field of surrounding rock by theoretical calculation [15-17]. According to the creep mechanism of rock and the rheological control principle of soft rock, some scholars have established the optimal support calculation method for soft rock and solved the optimal support force and the allowable maximum displacement of surrounding rock [18-21]. Among them, the DP criteria not only eliminates the singularity of the yield surface of the hexagonal pyramid, but also reflects the effect of intermediate principal stress and hydrostatic pressure, which has been widely used in underground engineering [22-24]. However, the existing optimal support solutions for soft rock roadways have not discussed the differences in DP criteria [25-27].

The instability of excavation is usually caused by the excessive concentration of stress in the rock mass near the excavation, the excessive stress of supporting components, or the change of rock deformation and strength characteristics [28-32]. The deformation pressure of viscoelastic rock mass on underground roadway support depends on the properties of the surrounding rock and the rock-support interaction. Therefore, based on DP series criteria reflecting intermediate principal stress, this paper deduces the analytical solution of optimal support force and the allowable maximum displacement of surrounding rock in a circular roadway. In doing so, it compares different DP criteria by an engineering example and discusses the effects of long-term strength, cohesion, and internal friction angle of soft rock on the maximum plastic zone radius and allowable maximum displacement of a roadway. The research results can provide theoretical guidance for the rational design and optimization of soft rock roadway supports.

\section{Drucker-Prager Yield Criteria}

The yield surface of the Mohr-Coulomb (MC) yield criterion is an irregular hexagonal pyramid in three-dimensional stress space. To eliminate the singularity of the yield surface on the cone top and the ridgeline, Drucker and Prager proposed a smooth conical yield surface that is inscribed in the MC yield criterion hexagonal pyramid [33]. According to the relative positional relationship between the DP yield criterion and the MC yield criterion on the $\pi$ plane, the DP yield criteria are derived [34]. The DP yield criteria can be given by:

$$
\alpha I_{1}+\sqrt{J_{2}}=k
$$

where the parameters $\alpha$ and $k$ are related to the cohesion $c$ and the internal friction angle $\varphi$ of the surrounding rock. According to the matching relationship with the MC criterion, the corresponding parameter expressions are shown in Table $1 . I_{1}$ is the first invariant of the stress tensor, $I_{1}=\sigma_{1}+\sigma_{2}+\sigma_{3} ; J_{2}$ is the second invariant of stress deviator, $J_{2}=\left[\left(\sigma_{1}-\sigma_{2}\right)^{2}+\left(\sigma_{2}-\sigma_{3}\right)^{2}+\left(\sigma_{3}-\sigma_{1}\right)^{2}\right] / 6$; and $\sigma_{1}, \sigma_{2}$, and $\sigma_{3}$ are the large, medium, and small principal stresses of the surrounding rock, respectively.

Table 1. Parameter expressions of Drucker-Prager yield criteria.

\begin{tabular}{|c|c|c|c|}
\hline Serial Number & Criterion Types & $\alpha$ & $k$ \\
\hline DP1 & $\begin{array}{l}\text { The MC criterion based on external corner } \\
\text { circumscribed, a circle yield criterion }\end{array}$ & $\frac{2 \sin \varphi}{\sqrt{3}(3-\sin \varphi)}$ & $\frac{6 c \cos \varphi}{\sqrt{3}(3-\sin \varphi)}$ \\
\hline DP2 & $\begin{array}{l}\text { The MC criterion based on inner corner } \\
\text { circumscribed, a circle yield criterion }\end{array}$ & $\frac{2 \sin \varphi}{\sqrt{3}(3+\sin \varphi)}$ & $\frac{6 c \cos \varphi}{\sqrt{3}(3+\sin \varphi)}$ \\
\hline DP3 & $\begin{array}{l}\text { The MC criterion based on matching circles, } \\
\text { for plain strain problems with associated } \\
\text { flow rules }\end{array}$ & $\frac{\sin \varphi}{\sqrt{3} \sqrt{3+\sin ^{2} \varphi}}$ & $\frac{3 c \cos \varphi}{\sqrt{3} \sqrt{3+\sin ^{2} \varphi}}$ \\
\hline DP4 & $\begin{array}{c}\text { The MC criterion based on equivalent area, } \\
\text { a circle yield criterion }\end{array}$ & $\frac{2 \sqrt{3} \sin \varphi}{\sqrt{2 \sqrt{3} \pi\left(9-\sin ^{2}()\right)}}$ & $\frac{2 \sqrt{3} c \cos \varphi}{\sqrt{2 \sqrt{3} \pi\left(9-\sin ^{2}\right.}}$ \\
\hline DP5 & $\begin{array}{l}\text { The MC criterion based on matching circles, } \\
\text { for plain strain problems with } \\
\text { non-associated flow rules }\end{array}$ & $\begin{array}{l}\sqrt{2 \sqrt{3} \pi(9-\sin } \\
\frac{\sin \varphi}{3}\end{array}$ & $\sqrt{2} \sqrt{3} \pi\left(9-\sin ^{2}\right.$ \\
\hline
\end{tabular}


The expression of the DP criteria under plane strain condition is as follows:

$$
\sigma_{1}=M \sigma_{3}+N
$$

where $M=\frac{1+3 \alpha}{1-3 \alpha}$ and $N=\frac{2 k}{1-3 \alpha}$. Because the internal friction angle $\varphi$ is always greater than $0, \alpha \neq 0$ and $M \neq 1$.

\section{Optimum Support Calculation of Roadway}

\subsection{Basic Assumptions}

To carry out the elastic-plastic analysis of surrounding rock, the following assumptions are made:

(1) The cross section of the roadway is circular, and the length is infinite, so it can be simplified as a plane strain problem.

(2) The surrounding rock of the roadway is a continuous, homogeneous, and isotropic elastic-plastic material.

(3) Ignoring the effects of the surrounding rock weight on the yield, the original rock stress can be simplified as a uniform stress distribution. The roadway is under the conditions of uniform in situ stress and support force.

\subsection{Elastic-Plastic Analysis}

Taking the circular roadway under the combined action of uniform in situ stress $p_{0}$ and uniform support force $p_{i}$ shown in Figure 1 as an example, the elastic-plastic stresses of the surrounding rock during excavation are solved in this section. In Figure $1, r_{i}$ is the excavation radius of the roadway; $R$ is the radius of the plastic zone of the surrounding rock; $u_{0}$ is the displacement of the roadway wall; and $\sigma_{r}$ and $\sigma_{\theta}$ are the radial and tangential stresses, respectively.

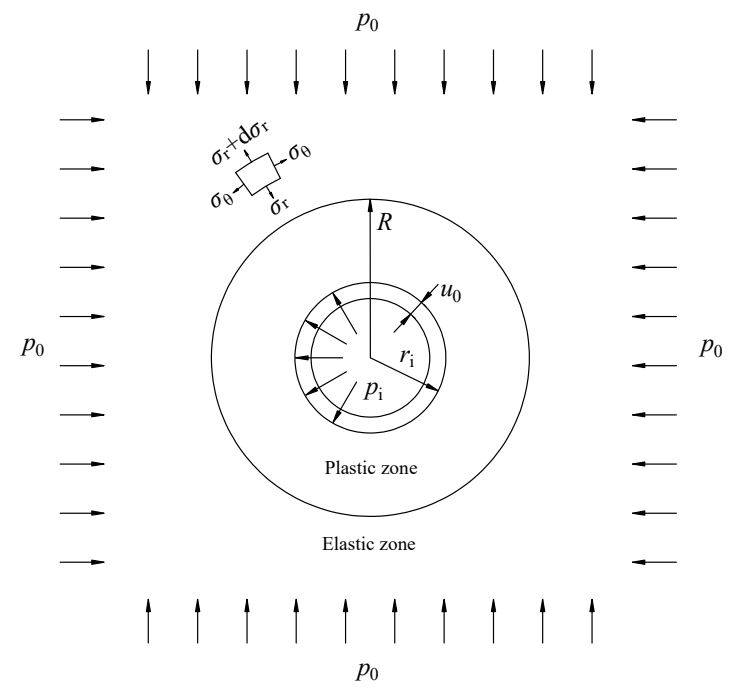

Figure 1. Elastic-plastic analysis model of circular roadway. $p_{0}$ : uniform in situ stress, $p_{i}$ : uniform support force, $u_{0}$ : the displacement of the roadway wall, $\sigma_{r}$ : radial stresses, $\sigma_{\theta}$ : tangential stresses, $r_{i}$ : the excavation radius of the roadway, $R$ : the radius of the plastic zone of the surrounding rock.

In the plastic zone of the surrounding rock, the tangential stress $\sigma_{\theta}$ and the radial stress $\sigma_{r}$ are the maximum and minimum principal stresses, respectively. Equation (2) can be written as:

$$
\sigma_{\theta}=M \sigma_{r}+N
$$

The differential equation of equilibrium for the axisymmetric problem can be expressed as:

$$
\frac{\mathrm{d} \sigma_{r}}{\mathrm{~d} r}+\frac{\sigma_{r}-\sigma_{\theta}}{r}=0
$$


where $r$ is the radius of calculation area of the circular roadway.

By taking the stress at the inner wall of roadway as the boundary condition, the stress field distribution in the plastic zone is obtained as follows [12,13]:

$$
\left.\begin{array}{c}
\sigma_{r}^{\mathrm{p}}=\left(p_{i}+\frac{N}{M-1}\right)\left(\frac{r}{r_{i}}\right)^{M-1}-\frac{N}{M-1} \\
\sigma_{\theta}^{\mathrm{p}}=M\left(p_{i}+\frac{N-1}{M-1}\left(\frac{r}{r_{i}}\right)^{M-1}-\frac{N}{M-1}\right.
\end{array}\right\}
$$

where $p_{i}$ is the support force; $r_{i}$ is the radius of roadway; and $\sigma_{r}^{\mathrm{p}}$ and $\sigma_{\theta}^{\mathrm{p}}$ are the radial stress and tangential stress in the plastic zone, respectively.

Assuming that the radial stress at the interface between the elastic zone and the plastic zone of surrounding rock is $\sigma_{r}^{\mathrm{e}-\mathrm{p}}$, based on thick-walled cylinder theory, the stress field distribution in the elastic zone can be obtained as follows:

$$
\left.\begin{array}{l}
\sigma_{r}^{\mathrm{e}}=p_{0}-\left(p_{0}-\sigma_{r}^{\mathrm{e}-\mathrm{p}}\right) \frac{R^{2}}{r^{2}} \\
\sigma_{\theta}^{\mathrm{e}}=p_{0}+\left(p_{0}-\sigma_{r}^{\mathrm{e}-\mathrm{p}}\right) \frac{R^{2}}{r^{2}}
\end{array}\right\}
$$

where $p_{0}$ is the uniform in situ stress; $R$ is the radius of the plastic zone; $\sigma_{r}^{\mathrm{e}}$ and $\sigma_{\theta}^{\mathrm{e}}$ are the radial stress and tangential stress in the elastic zone. Respectively; and $E$ and $v$ are the elastic modulus and Poisson's ratio of the surrounding rock, respectively.

Since the stress at the elastic-plastic interface of surrounding rock is continuous, the expressions of radial stress at the elastic-plastic interface and the radius of the plastic zone can be obtained as follows:

$$
\begin{gathered}
\sigma_{r}^{\mathrm{e}-\mathrm{p}}=\frac{2 p_{0}-N}{M+1} \\
R=r_{i}\left(\frac{\sigma_{r}^{\mathrm{e}-\mathrm{p}}+\frac{N}{M-1}}{p_{i}+\frac{N}{M-1}}\right)^{\frac{1}{M-1}}
\end{gathered}
$$

By substituting Equation (7) into Equation (6), the stress solutions in the elastic zone are obtained as follows:

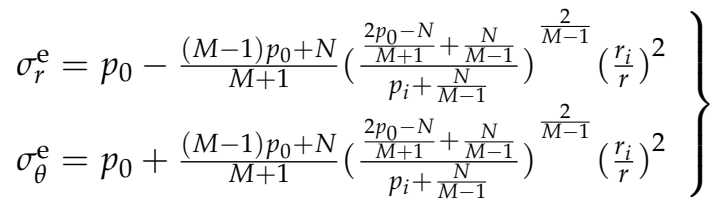

During the excavation of the roadway, the support force of surrounding rock is 0 , and the initial plastic zone radius can be calculated by Equation (8). The initial plastic zone radius $R_{0}$ can be expressed as follows:

$$
R_{0}=r_{i}\left[1+\frac{(M-1)\left(2 p_{0}-N\right)}{(M+1) N}\right]^{\frac{1}{M-1}}
$$

In the support stage, the elastic stress solution at the elastic-plastic interface can be obtained by substituting Equation (10) with Equation (9). The radial and tangential stresses at the elastic-plastic interface are as follows:

$$
\left.\begin{array}{l|l}
\sigma_{r}^{\mathrm{e}} & r=R_{0}=p_{0}-\frac{(M-1) p_{0}+N}{M+1}\left[\frac{N}{(M-1) p_{i}+N}\right]^{\frac{2}{M-1}} \\
\sigma_{\theta}^{\mathrm{e}} & r=R_{0}=p_{0}+\frac{(M-1) p_{0}+N}{M+1}\left[\frac{N}{(M-1) p_{i}+N}\right]^{\frac{2}{M-1}}
\end{array}\right\}
$$

For the plane strain problem, the Z-direction strain is 0 , meaning that the intermediate principal stress $\sigma_{z}$ can be derived by Hooke's law as follows:

$$
\sigma_{z}=v\left(\sigma_{\theta}+\sigma_{r}\right)
$$


The following equation can be obtained by ordering the principal stresses at the elastic-plastic interface:

$$
\sigma_{1}=\left.\sigma_{\theta}^{\mathrm{e}}\right|_{r=R_{0}}, \sigma_{2}=\left.\sigma_{z}^{\mathrm{e}}\right|_{r=R_{0}}, \sigma_{3}=\left.\sigma_{r}^{\mathrm{e}}\right|_{r=R_{0}}
$$

Then, combined with Equations (11)-(13), the average principal stress $\sigma_{m}$ can be obtained as follows:

$$
\sigma_{m}=\frac{\sigma_{1}+\sigma_{2}+\sigma_{3}}{3}=\frac{2(1+v)}{3} p_{0}
$$

\subsection{Optimal Support Solution}

A creep is a special form of elastic-plastic deformation of rock, which is a phenomenon where the strain increases with time under the condition of keeping the stress constant. For example, soft rock or hard rock under a high level of stress usually have obvious creep characteristics and show serious extrusion deformation from all directions of underground engineering, which often leads to the instability and failure of supports [35,36]. Therefore, this kind of rock can be considered as an elastic-plastic material with rheological properties. The typical creep curve of rock mainly includes three stages: temporary creep (AB), stable creep (BC), and accelerated creep (CD), as shown in Figure 2.

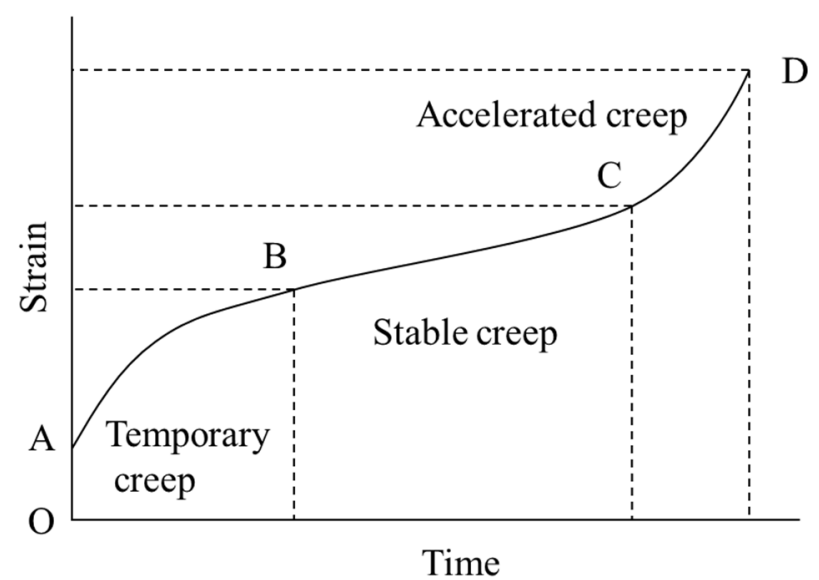

Figure 2. Typical creep curve of rock.

Many engineering practices show that excessive harmful deformation is the main reason for the instability of underground engineering. The establishment and application of the creep model are some of the core components in the study of the deformation characteristics of soft rock. The steady creep criterion expressed by the third invariant of deviator stress is as follows [30]:

$$
\begin{gathered}
\sqrt[3]{\frac{27}{2} J_{3}} \leq \sigma_{L} \\
J_{3}=\left(\sigma_{1}-\sigma_{\mathrm{m}}\right)\left(\sigma_{2}-\sigma_{\mathrm{m}}\right)\left(\sigma_{3}-\sigma_{\mathrm{m}}\right)
\end{gathered}
$$

where $\sigma_{L}$ is the long-term strength of rock and $J_{3}$ is the third invariant of the deviator stress.

By substituting Equations (13) and (14) into Equation (15) and making both sides of the equation equal, the optimum support force of roadway is obtained as follows:

$$
p_{i-\min }=\frac{N}{M-1}\left[\frac{1}{3} \sqrt{\frac{\sigma_{L}^{3}}{(1-2 v) p_{0}}+(1-2 v)^{2} p_{0}^{2}}\left[\frac{N}{M-1}+\left(\frac{M-1}{M+1}\right) p_{0}\right]\right]^{-1}-\frac{N}{M-1}
$$


The optimal support state occurs when the roadway support force $p_{i}$ is equal to the optimum support force $p_{i-\min }$. In this case, the radius of the plastic zone is:

$$
R_{\max }=r_{i}\left[\left(\frac{2 p_{0}-N}{M+1}+\frac{N}{M-1}\right)\left(p_{i-\min }+\frac{N}{M-1}\right)^{-1}\right]^{\frac{1}{M-1}}
$$

where $R_{\max }$ is the maximum radius of the plastic zone.

Based on thick-walled cylinder theory, the displacement in the elastic zone is:

$$
u^{\mathrm{e}}=\frac{1+v}{E}\left(p_{0}-\sigma_{r}^{\mathrm{e}-\mathrm{p}}\right) \frac{R^{2}}{r}
$$

At the elastic-plastic interface, $r=R$, and the displacement of surrounding rock at the elastic-plastic interface is:

$$
u^{\mathrm{e}-\mathrm{p}}=\frac{(1+v) R}{E}\left(p_{0}-\sigma_{r}^{\mathrm{e}-\mathrm{p}}\right)
$$

In the optimum support condition, the initial elastic displacement at the elastic-plastic interface is as follows:

$$
u_{0}^{\mathrm{e}}=\frac{(1+v) R_{\max }}{E} \frac{(M-1) p_{0}+N}{M+1}
$$

The creep modulus of rock can be obtained by laboratory rheological testing. By replacing the elastic modulus $E$ of Equation (21) with the creep modulus $E_{\mathrm{c}}$, the creep displacement at the elastic-plastic interface can be obtained as follows:

$$
u^{\mathrm{c}}=\frac{(1+v) R_{\max }}{E_{\mathrm{c}}} \frac{(M-1) p_{0}+N}{M+1}
$$

The displacement of the plastic zone is composed of initial elastic displacement and stable creep displacement. According to Equation (21) and Equation (22), the stable displacement of roadway can be calculated as follows:

$$
\triangle u=u^{\mathrm{c}}-u_{0}^{\mathrm{e}}=\frac{(1+v) R_{\max }\left[(M-1) p_{0}+N\right]}{M+1}\left(\frac{E-E_{c}}{E \cdot E_{c}}\right)
$$

Taking $\left.u\right|_{r=R_{\max }}=\Delta u$ as the displacement boundary condition, the displacement of the roadway wall in the optimum support condition is obtained as:

$$
u_{0-\max }=\frac{R_{\max }}{r_{i}} \triangle u=\frac{(1+v) R_{\max }^{2}\left[(M-1) p_{0}+N\right]}{(M+1) r_{i}}\left(\frac{E-E_{c}}{E \cdot E_{c}}\right)
$$

It can be seen that different DP yield criteria correspond to different parameters, $M$ and $N$. By substituting Equation (17) into Equation (18) to obtain the maximum radius of plastic zone $R_{\max }$, and then substituting Equation (18) into Equation (24), the allowable maximum displacement at the roadway wall can be obtained.

\section{Example Studies and Discussion}

\subsection{Roadway Parameters}

The Beizao Coal Mine is located in Longkou City, Shandong Province, China, which is a typical soft rock mine with complex geological conditions; especially with continuous extensions to mining level, roadway deformation is a prominent problem. Taking the soft rock roadway in the Beizao Coal Mine as an engineering example, the effects of the DP criteria and the mechanical parameters of surrounding rock on roadway support can be analyzed. The geometric and mechanical parameters of the roadway are shown in Table 2. Yieldable U-shaped steel ribs are used to support the roadway and the in situ measured roadway wall displacement is $18.7 \mathrm{~mm}$. 
Table 2. Geometrical and mechanical parameters.

\begin{tabular}{ccc}
\hline Symbol & Description & Value \\
\hline$r_{i} / \mathrm{m}$ & Excavation radius & 2.0 \\
$p_{0} / \mathrm{MPa}$ & In situ stress & 5.6 \\
$E / \mathrm{MPa}$ & Elastic modulus & 1500 \\
$E_{c} / \mathrm{MPa}$ & Creep modulus & 400 \\
$v$ & Poisson's ratio & 0.24 \\
$c / \mathrm{MPa}$ & Cohesion & 0.71 \\
$\varphi /{ }^{\circ}$ & Internal friction angle & 23.6 \\
$\sigma_{c} / \mathrm{MPa}$ & Uniaxial compressive strength & 29.0 \\
$\sigma_{L} / \mathrm{MPa}$ & Long-term strength & 6.38 \\
\hline
\end{tabular}

\subsection{The Effect of Yield Criteria}

The calculation results for the optimal support force, maximum plastic zone radius, and allowable maximum displacement of surrounding rock under different DP criteria are shown in Table 3.

Table 3. Calculation results of different DP yield criteria.

\begin{tabular}{cccc}
\hline Serial Number & $p_{\boldsymbol{i}-\mathbf{m i n}} / \mathbf{M P a}$ & $\boldsymbol{R}_{\mathbf{m a x}} / \mathbf{m}$ & $\boldsymbol{u}_{\mathbf{0}-\mathbf{m a x}} / \mathbf{m m}$ \\
\hline DP1 & 0.76 & 2.33 & 23.69 \\
DP2 & 0.20 & 3.71 & 46.03 \\
DP3 & 0.16 & 4.06 & 52.72 \\
DP4 & 0.25 & 3.43 & 41.10 \\
DP5 & 0.18 & 3.85 & 48.66 \\
\hline
\end{tabular}

It can be seen that the optimal support force, the maximum radius of the plastic zone, and allowable maximum displacement calculated by different DP criteria are different. The optimal supporting force obtained by the DP1 criterion is the largest, while that obtained by the DP3 criterion is the smallest. The optimum support force of the DP3 criterion is only $21 \%$ of the DP1 criterion. The effect of intermediate principal stress $\sigma_{2}$ on surrounding rock strength is equal to the minimum principal stress $\sigma_{3}$ according to the DP1 criterion, which will exaggerate the influence of intermediate principal stress. Therefore, the maximum plastic zone radius and allowable maximum displacement obtained by the DP1 criterion are the smallest of the DP series criteria. The maximum plastic zone radius calculated by the DP3 criterion is 1.74 times that of the DP1 criterion, and the allowable maximum displacement is 2.23 times that of the DP1 criterion. This means that the DP1 criterion and the DP3 criterion are the upper and lower limits of the DP series criteria respectively. When the DP criteria are used for the elastic-plastic analysis of roadway surrounding rock, the appropriate DP yield criterion should be selected according to the actual engineering background and mechanical parameters of surrounding rock.

\subsection{The Effect of Long-Term Strength}

Figure 3 shows the rule of variation of the optimal support force and allowable maximum displacement under different long-term strengths. It can be seen that the larger the long-term strength is, the smaller the optimal support force is and the larger the allowable maximum displacement is. In other words, the greater the long-term strength of surrounding rock is, the more stable the roadway is. From Figure 3a, it can be seen that the overall performance of the optimal support force is DP1 > DP4 > DP2 > DP5 > DP3 With the increase in the long-term strength of surrounding rock, the optimal support forces calculated by different DP criteria become closer and closer, and will eventually completely coincide and achieve the ideal state without support. The reason for this change is that the larger the long-term strength of rock mass is, the smaller the plastic zone of roadway is, which leads to the weakening of the effect of the yield criterion. As can be seen from Figure $3 b$, the allowable maximum displacement is DP3 $>$ DP5 $>$ DP2 $>$ DP4 $>$ DP1. The 
results of the DP3 criterion are relatively conservative. Using the DP3 criterion in roadway support design can improve safety, but will increase the support cost.

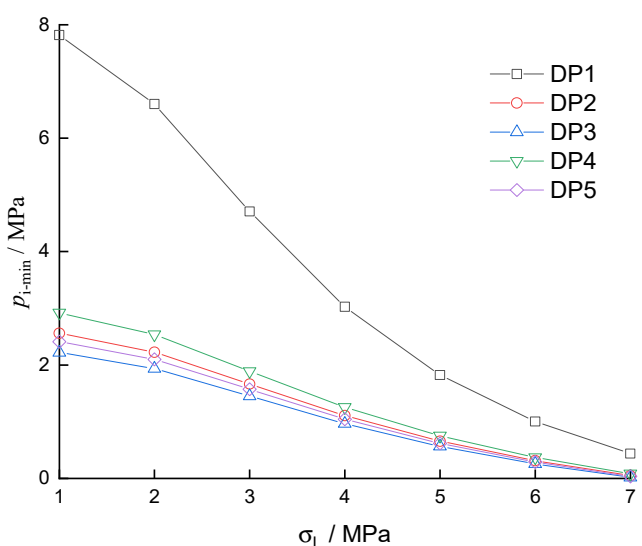

(a)

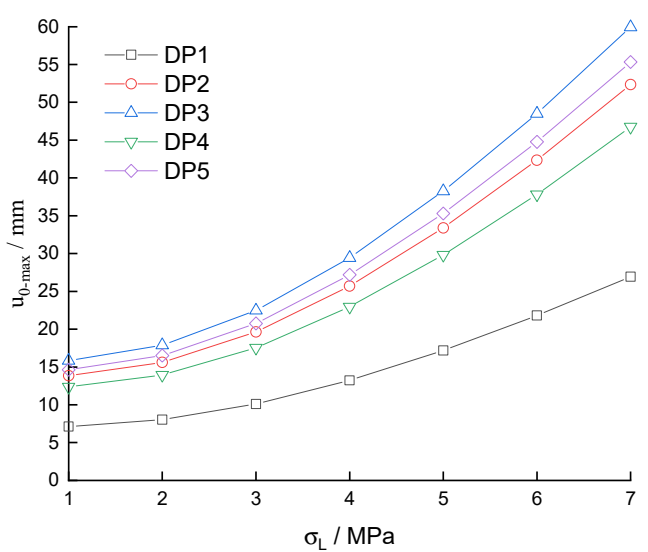

(b)

Figure 3. Effect of long-term strength on support: (a) optimal support force; (b) allowable maximum displacement.

The long-term strength of rock has a key impact on the optimal support parameters of the roadway. Under certain conditions, the surrounding rock can reach a stable creep stage by relying on its own strength without any support. The influence of surrounding rock cohesion and internal friction angle on the optimal support parameters of roadway is also very important, and the influence of cohesion becomes more prominent. In practical engineering, the real strength parameters of rock should be measured reasonably, and their variability should be considered.

\subsection{The Effect of Strength Parameters}

Figures 4 and 5 show the variation in the maximum plastic zone radii and allowable maximum displacement under different cohesion and internal friction angles, respectively. It can be seen that the influence trend of cohesion and internal friction angle on roadway deformation is roughly the same; that is, with the increase in cohesion or internal friction angle, the radius of the maximum plastic zone is smaller and smaller, and the allowable maximum displacement is also gradually reduced. The reason for this change is that the increase in cohesion or internal friction angle increases the bearing capacity of rock mass, thus reducing the failure range and restraining the plastic deformation of surrounding rock.

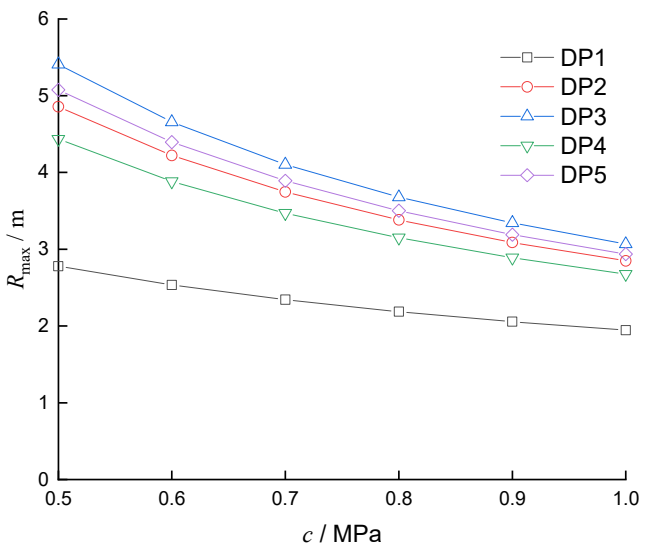

(a)

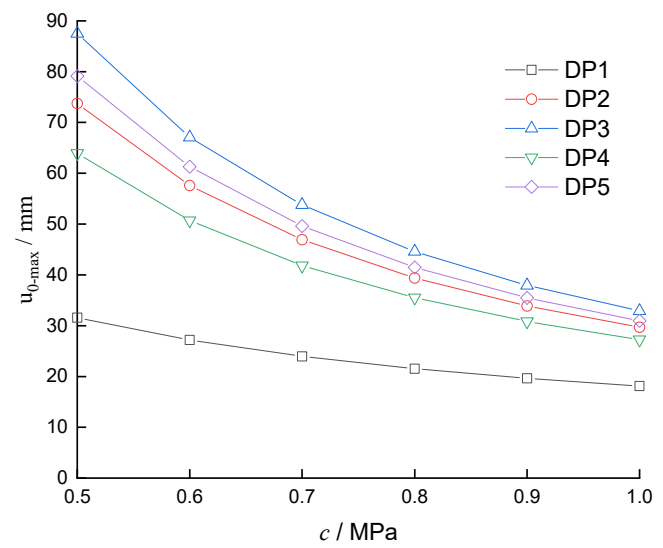

(b)

Figure 4. Effect of cohesion on radius and maximum displacement of plastic zone: (a) plastic zone radius; (b) allowable maximum displacement. 


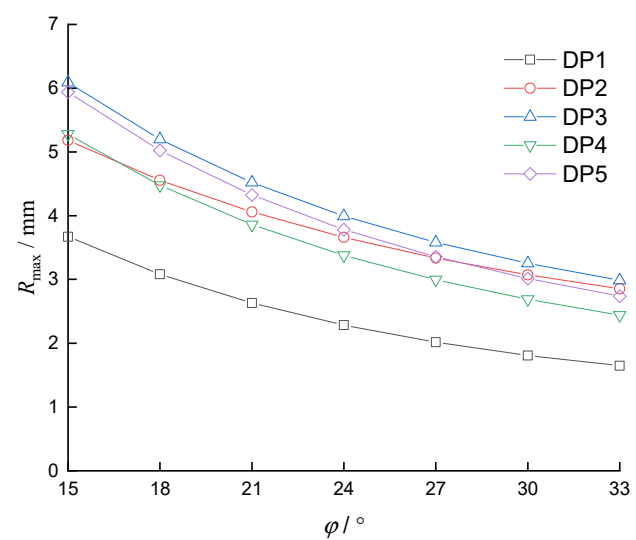

(a)

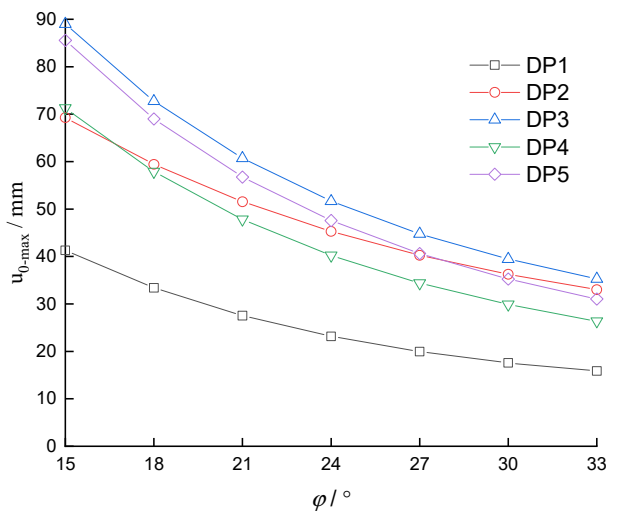

(b)

Figure 5. Effect of internal friction angle on radius and maximum displacement of plastic zone: (a) plastic zone radius; (b) allowable maximum displacement.

Taking the DP1 criterion as an example, when the cohesion increases from $0.5 \mathrm{MPa}$ to $1.0 \mathrm{MPa}$, the radius of the plastic zone decreases from $2.78 \mathrm{~m}$ to $1.95 \mathrm{~m}$, which is a reduction of nearly $30 \%$. The allowable maximum displacement was reduced by $43 \%$ from $31.58 \mathrm{~mm}$ to $18.10 \mathrm{~mm}$. When the internal friction angle increases from 15 to 33 degrees, the radius of plastic zone decreases from $3.67 \mathrm{~m}$ to $1.65 \mathrm{~m}$, a reduction of $55 \%$. The allowable maximum displacement is reduced from $41.30 \mathrm{~mm}$ to $15.86 \mathrm{~mm}$, which is a decrease of $62 \%$. It can be seen that the strength parameters of rock mass have great influence on the roadway support. The mechanical properties of engineering surrounding rock should be fully considered in support design. For example, the strength of surrounding rock can be improved by grouting, which can effectively reduce the deformation of the roadway.

\subsection{Novelty and Comparability Analysis}

Based on the DP yield criteria and the steady-state creep criterion expressed by the third invariant of deviatoric stress, the theoretical solutions of optimal support pressure and allowable maximum displacement of surrounding rock are derived. The theoretical solution can consider different degrees of intermediate principal stress effects and the selection of different DP strength criteria. The formula is concise and the parameters are easy to determine, which has important theoretical and practical engineering significance.

The intermediate principal stress significantly affects the optimal support parameters of a roadway. The greater the effect of intermediate principal stress is, the smaller the optimal support force of the corresponding roadway will be and the greater the allowable maximum displacement of the surrounding rock will be. Therefore, the calculation results of the Mohr-Coulomb criterion are too conservative without considering the influence of intermediate principal stress. The DP strength criterion fully considers the influence of intermediate principal stress, and the calculation results can better demonstrate the strength potential of the surrounding rock. In addition, the optimal roadway support solution of the $J_{2}$ stable creep criterion needs to add non-negative conditions under the root sign, meaning that the $J_{3}$ criterion solution has a wider application range. According to the $J_{3}$ criterion, the optimal support force of a roadway is large and the allowable maximum displacement of the surrounding rock is small.

\section{Conclusions}

(1) An analytical solution of optimal support force and allowable maximum displacement of surrounding rock for circular roadway based on the DP series criteria is proposed. The proposed optimal support solution can not only reflect the intermediate principal stress reasonably, but also can allow us to compare and discuss the influence of different DP criteria on the calculation results. The new theoretical solution can consider different intermediate principal stress effects and different DP 
strength criteria, and the parameters are easier to determine. It has a wider range of applications, and the calculation results can better demonstrate the strength potential of the surrounding rock.

(2) The long-term strength of rock surrounding a roadway has a significant impact on the optimal support force and the allowable maximum displacement. The higher the long-term strength of rock surrounding a roadway is, the smaller the optimal support force will be and the larger the allowable maximum displacement will be. When the calculated long-term strength of soft rock can ensure that the deformation of the roadway does not exceed the allowable maximum displacement, the roadway can maintain long-term stability without support.

(3) The influence of the parameters of surrounding rock on roadway support and deformation is also significant. With the increase in cohesion or internal friction angle, the radius of the plastic zone of surrounding rock becomes smaller and smaller and the allowable maximum displacement also decreases gradually. The use of grouting and other means to improve the strength of surrounding rock can effectively reduce the deformation of a roadway. The analytical solution can also provide theoretical guidance for engineering practice.

Author Contributions: Conceptualization, M.M. and Q.G.; methodology, M.M. and Q.G.; validation, M.M. and Q.G.; formal analysis, J.P. and C.M.; investigation, J.P. and C.M.; resources, Q.G. and M.C.; writing—original draft, M.M. and Q.G.; writing—review and editing, Q.G. and J.P.; supervision, M.C.; project administration, M.C.; funding acquisition, Q.G. and M.C. All authors have read and agreed to the published version of the manuscript.

Funding: This research was funded by the Fundamental Research Funds for the Central Universities (Grant No. FRF-IDRY-20-032) and the National Natural Science Foundation of China (No. 51974014).

Data Availability Statement: Not applicable.

Conflicts of Interest: The authors declare that they have no conflict of interest.

\section{References}

1. Yang, X.; Pang, J.; Liu, D.; Liu, Y.; Tian, Y.; Ma, J.; Li, S. Deformation mechanism of roadways in deep soft rock at Hegang Xing'an Coal Mine. Int. J. Min. Sci. Technol. 2013, 23, 307-312. [CrossRef]

2. Shen, B. Coal mine roadway stability in soft rock: A case study. Rock Mech. Rock Eng. 2014, 47, 2225-2238. [CrossRef]

3. Yang, S.Q.; Chen, M.; Jing, H.W.; Chen, K.F.; Meng, B. A case study on large deformation failure mechanism of deep soft rock roadway in Xin'An coal mine, China. Eng. Geol. 2017, 217, 89-101. [CrossRef]

4. Cao, P.; Youdao, W.; Yixian, W.; Haiping, Y.; Bingxiang, Y. Study on nonlinear damage creep constitutive model for high-stress soft rock. Environ. Earth Sci. 2016, 75, 900. [CrossRef]

5. Ma, D.; Zhang, J.; Duan, H.; Huang, Y.; Li, M.; Sun, Q.; Zhou, N. Reutilization of gangue wastes in underground backfilling mining: Overburden aquifer protection. Chemosphere 2021, 264, 128400. [CrossRef]

6. Wang, Q.; Pan, R.; Jiang, B.; Li, S.C.; He, M.C.; Sun, H.B.; Wang, L.; Qin, Q.; Yu, H.C.; Luan, Y.C. Study on failure mechanism of roadway with soft rock in deep coal mine and confined concrete support system. Eng. Fail. Anal. 2017, 81, 155-177. [CrossRef]

7. Chen, Y.; Meng, Q.; Xu, G.; Wu, H.; Zhang, G. Bolt-grouting combined support technology in deep soft rock roadway. Int. J. Min. Sci. Technol. 2016, 26, 777-785. [CrossRef]

8. Wang, C.; Wang, Y.; Lu, S. Deformational behaviour of roadways in soft rocks in underground coal mines and principles for stability control. Int. J. Rock Mech. Min. Sci. 2000, 37, 937-946. [CrossRef]

9. Kang, H.P.; Lin, J.; Fan, M.J. Investigation on support pattern of a coal mine roadway within soft rocks-A case study. Int. J. Coal Geol. 2015, 140, 31-40. [CrossRef]

10. Yoshinaka, R.; Tran, T.V.; Osada, M. Non-linear, stress-and strain-dependent behavior of soft rocks under cyclic triaxial conditions. Int. J. Rock Mech. Min. Sci. 1998, 35, 941-955. [CrossRef]

11. Walton, G.; Delaloye, D.; Diederichs, M.S. Development of an elliptical fitting algorithm to improve change detection capabilities with applications for deformation monitoring in circular tunnels and shafts. Tunn. Undergr. Space Technol. 2014, 43, 336-349. [CrossRef]

12. Wu, K.; Shao, Z.; Qin, S. An analytical design method for ductile support structures in squeezing tunnels. Arch. Civ. Mech. Eng. 2020, 20, 1-13. [CrossRef]

13. Wu, K.; Shao, Z.; Qin, S.; Zhao, N.; Hu, H. Analytical-Based Assessment of Effect of Highly Deformable Elements on Tunnel Lining Within Viscoelastic Rocks. Int. J. Appl. Mech. 2020, 12, 2050030. [CrossRef] 
14. Wu, K.; Shao, Z.; Qin, S.; Li, B. Determination of deformation mechanism and countermeasures in silty clay tunnel. J. Perform. Constr. Facil. 2020, 34, 04019095. [CrossRef]

15. Song, F.; Wang, H.; Jiang, M. Analytically-based simplified formulas for circular tunnels with two liners in viscoelastic rock under anisotropic initial stresses. Constr. Build. Mater. 2018, 175, 746-767. [CrossRef]

16. Song, F.; Wang, H.; Jiang, M. Analytical solutions for lined circular tunnels in viscoelastic rock considering various interface conditions. Appl. Math. Model. 2018, 55, 109-130. [CrossRef]

17. Pan, J.; Guo, Q.; Ren, F.; Cai, M. Comparative analysis of different strength criteria for deep-buried rock roadway under seepage. J. China Coal Soc. 2019, 44, 3369-3378.

18. Xu, S.Q.; Yu, M.H. The effect of the intermediate principal stress on the ground response of circular openings in rock mass. Rock Mech. Rock Eng. 2006, 39, 169-181. [CrossRef]

19. Ma, D.; Duan, H.Y.; Zhang, J.X.; Feng, X.J.; Huang, L. Experimental investigation of creep-erosion coupling mechanical properties of water inrush hazards in fault fracture rock masses. Chin. J. Rock Mech. Eng. 2021, 40, 1751-1763.

20. Park, K.H.; Kim, Y.J. Analytical solution for a circular opening in an elastic-brittle-plastic rock. Int. J. Rock Mech. Min. Sci. 2006, 43, 616-622. [CrossRef]

21. Sharan, S.K. Exact and approximate solutions for displacements around circular openings in elastic-brittle-plastic Hoek-Brown rock. Int. J. Rock Mech. Min. Sci. 2005, 42, 542-549. [CrossRef]

22. Guo, Q.; Pan, J.; Wu, X.; Xi, X.; Cai, M. A new unified solution for circular tunnels based on generalized SMP criterion considering the strain softening and dilatancy. Adv. Civ. Eng. 2019, 2019, 1684707. [CrossRef]

23. Pan, J.; Gao, Z.; Ren, F. Effect of strength criteria on surrounding rock of circular roadway considering strain softening and dilatancy. J. China Coal Soc. 2018, 43, 3293-3301.

24. Fan, H.; Wang, L.; Wang, K. Stability Analysis of Surrounding Rock in Circular Tunnels Based on Critical Support Pressure. Adv. Civ. Eng. 2020, 2020, 8870928. [CrossRef]

25. Qiuyan, F.; Weishen, Z. Method for calculating optimum support of soft rock. Chin. J. Geotech. Eng. 1997, 19, 77-83.

26. Cui, X.H.; Gao, Y.F.; Fan, Q.Z.; Niu, X.L. Optimum calculating method for constant resistant supporting of roadway surrounding rock. Chin. J. Geotech. Eng. 2006, 28, 674-678.

27. Zeng, K.; Yang, W.; Zhang, C.; Dai, H. Optimal Support in Soft Rock Tunnel Based on the Unified Strength Theory and Steady Creep Guideline. Adv. Eng. Sci. 2018, 50, 62-70.

28. Filcek, H.; Kwaśniewski, M.A. Fundamentals of Mine Roadway Support Design: Rock-Support Interaction Analysis. In Analysis and Design Methods; Pergamon: Bergama, Turkey, 1993; pp. 671-699.

29. Pan, J.; Wu, X.; Guo, Q.; Xi, X.; Cai, M. Uniaxial experimental study of the deformation behavior and energy evolution of conjugate jointed rock based on AE and DIC methods. Adv. Civ. Eng. 2020, 2020, 8850250. [CrossRef]

30. Guo, Q.; Pan, J.; Cai, M.; Zhang, Y. Analysis of Progressive Failure Mechanism of Rock Slope with Locked Section Based on Energy Theory. Energies 2020, 13, 1128. [CrossRef]

31. Guo, Q.; Pan, J.; Cai, M.; Zhang, Y. Investigating the effect of rock bridge on the stability of locked section slopes by the direct shear test and acoustic emission technique. Sensors 2020, 20, 638. [CrossRef]

32. Xi, X.; Wu, X.; Guo, Q.; Cai, M. Experimental investigation and numerical simulation on the crack initiation and propagation of rock with pre-existing cracks. IEEE Access 2020, 8, 129636-129644. [CrossRef]

33. Alejano, L.R.; Bobet, A. Drucker-Prager criterion. In The ISRM Suggested Methods for Rock Characterization, Testing and Monitoring: 2007-2014; Springer: Cham, Switzerland, 2012; pp. 247-252.

34. Jiang, H.; Xie, Y. A note on the Mohr-Coulomb and Drucker-Prager strength criteria. Mech. Res. Commun. 2011, 38, 309-314. [CrossRef]

35. Chu, Z.; Wu, Z.; Liu, Q.; Liu, B. Analytical Solutions for Deep-Buried Lined Tunnels Considering Longitudinal Discontinuous Excavation in Rheological Rock Mass. J. Eng. Mech. 2020, 146, 04020047. [CrossRef]

36. Chu, Z.; Wu, Z.; Liu, B.; Liu, Q. Coupled analytical solutions for deep-buried circular lined tunnels considering tunnel face advancement and soft rock rheology effects. Tunn. Undergr. Space Technol. 2019, 94, 103111. [CrossRef] 